\title{
HUMANOS QUE QUEREMOS SER. HUMANISMO, CIBORGUISMO E PÓS-HUMANISMO COMO TECNOLOGIAS DE SI
}

\section{HUMANS WE WANT TO BE. HUMANISM, CYBORGISM AND POSTHUMANISM AS TECHNOLOGIES OF THE SELF}

\section{Paulo Noboru de Paula Kawanishi ${ }^{* 1}$ Gil Vicente Nagai Lourenção**2}

\section{RESUMO}

Em momentos de transformações tecnocientíficas, o humano como espécie, como ideia ou como representação pode ser afetado. Entre as práticas envolvendo tecnologias que crescem atualmente, o biobacking é um termo potencial que engloba diferentes ações, representações e ideias e que de forma levemente sub-reptícia guarda certa premissa de atuar sobre o material orgânico [homo-coisa] com o objetivo de 'aprimorar' o ser humano, seja lá por meio de quantas múltiplas e diversas formas isso possa se dar. Este artigo em forma ensaística possui o objetivo de pensar sobre um dos processos de subjetivação de um sujeito pós-humano, partindo de um exemplo retirado do biobacking ocorrido em um evento na cidade de São Paulo. Para tal, pincelamos algumas referências sobre o ciborguismo enquanto um movimento que constrói a metáfora para uma subjetividade híbrida e, na sequência, passamos pelo conceito de pós-humanismo e duas de suas expressões mais proeminentes: o trans-humanismo e o pós-humano crítico. Ao final, argumentamos que, no caso de praticantes e personas hibridizadas pelo biobacking a noção de cuidado de si é um meio analítico de abordar o processo de subjetivação de um sujeito por meio das tecnologias de si.

Palavras-chave: subjetividade, ciborguismo, pós-humanismo.

\section{ABSTRACT}

In historical moments of technoscientific developments, the human can be affected as a species, as an idea or as a representation of himself. In these days, among the practices

\footnotetext{
* Doutorando em Linguística Aplicada pelo Instituto de Estudos da Linguagem (IEL) da Universidade Estadual de Campinas (UNICAMP), Campinas, SP, Brasil. pkawanishi@hotmail.com.br, https:// orcid.org/0000-0002-6726-1585

1. O presente trabalho foi realizado com apoio da Coordenação de Aperfeiçoamento de Pessoal de Nível Superior - Brasil (CAPES) - Código de Financiamento 001.

** Membro do Grupo de Estudos Interdisciplinares em Ciência e Tecnologia - GEICT-Unicamp, Campinas, SP, Brasil. gilvicenteworks@gmail.com, https://orcid.org/0000-0002-9685-1226

2. Pesquisador Consignado. Faculdade de Humanidades e Ciências Sociais, Departamento de História e Antropologia, Universidade de Tsukuba, Japão. Pesquisador de Pós doutorado pela Fundação de Amparo à Pesquisa do Estado de São Paulo, Fundação à qual agradeço pelo financiamento dessa pesquisa. Pesquisador no Departamento de Política Científica e Tecnológica, Unicamp. Doutor em Antropologia Social-UFSCar. Processo Fapesp: 2018/06952-7.
} 
involving technologies, the biohacking is a potential term that encompasses different actions and ideas, and it keeps a specific premise of acting on organic material [homo-thing] with the aim of 'improving' the human being, whether through how many different forms it may take. This essay has the objective of thinking about the process of subjectivization of a posthuman subject, starting from an example taken from a biohacking event occurred in São Paulo. To do so, we will draw some references about the cyborgism as a movement that enacts the metaphor for a hybrid subjectivity, and after that, we will go through the concept of posthumanism and two of its most interesting expressions: transhumanism and the posthuman critical. In the end, we will argue that in the case of practitioners and people hybridized by the biohacking, the notion of self-care is a logical way of approaching the subjectivization process of a subject through the technologies of the self.

Keywords: Subjectivity, cyborguism, posthumanism.

\section{INTRODUÇÃO}

Com notícias apontando o nascimento de crianças geneticamente modificadas na China $^{3}$, o avanço das biotecnologias se desdobra em uma questão que toca a todos nós: qual o futuro da espécie humana? Uma vez que certas tecnologias saíram das histórias de ficção científica e se encontram em nossa realidade, as possibilidades se multiplicam e os caminhos que a humanidade pode percorrer se tornam desconhecidos.

Além de crianças geneticamente modificadas, existem investimentos em diferentes tecnologias que podem, de um jeito ou de outro, "aprimorar" o ser humano. Tirando suas possíveis falhas e otimizando suas funções, a tecnologia se torna a principal aliada de nossa espécie para o futuro incerto. Pelo menos, é isso que as pessoas envolvidas com o movimento do trans-humanismo defendem.

A junção do humano com a máquina, projeto trans-humanista, encontra sua representação na figura do ciborgue. No entanto, por trás de sua proposta evolucionária, existem questões deixadas de lado. Todos os humanos serão aprimorados? Quem decide o que pode ou não ser aprimorado? Estaremos nas mãos das empresas fabricantes das tecnologias de aprimoramento? Enquanto questões como essas não são respondidas, o trans-humanismo constitui outras práticas e movimentos, como é o caso do biobacking.

Marcado pela premissa do controle de materiais biológicos por meio de diferentes técnicas, o biobacking se populariza, principalmente, em sua vertente mais branda, mas que, ao mesmo tempo, é a mais acessível. Cunhada de "biohacking de performance", trata-se de um conjunto de práticas que envolvem desde regimes e

3. Visto em https://g1.globo.com/ciencia-e-saude/noticia/2018/11/26/cientista-chines-alega-ter-criadoprimeiros-bebes-geneticamente-editados.ghtml. Acesso: 10/01/2019. 
controle de sono a medições de açúcar ou cafeína ingeridos. Essas práticas serviriam para agir sobre o corpo do indivíduo, seu sistema biológico, para potencializar suas capacidades físicas e/ou cognitivas. Ademais, o próprio indivíduo aplica esse corpo de saber sobre si mesmo, não necessitando de grandes laboratórios ou até mesmo de um acompanhamento médico.

Neste artigo, baseando-nos na descrição de uma pequena palestra sobre biobacking de performance, discorreremos sobre a possibilidade de refletir sobre um cuidado de si que constitui um sujeito pós-humano. Partimos da suspeita de que este, fundamentado em práticas de biohacking de performance, acaba seguindo o projeto trans-humanista de constituir um indivíduo em um sujeito pós-humano, cuja utilidade vai ao encontro das necessidades da lógica capitalista. O pós-humano do projeto trans-humanista não é um sujeito mais livre, mas sim, um sujeito mais produtivo para o capitalismo atual. Por outro lado - e há o outro lado -, desejamos apontar que o biohacking de performance tem uma inflexão local, no sujeito, e gera subjetividade.

Ao mesmo tempo, argumentaremos que pode haver a possibilidade de que o ciborgue/ biobacker não precise ipsis litteris ser o humano maquinizado que sustenta as condições de produção do capital. O biohacker, assim como, e seu congênere ciborgue, é um híbrido, e comporta as contradições que não encontram um lugar nas categorias dicotômicas clássicas, pois vazam das pequenas caixas nas quais tentamos mantê-las. É precisamente por essa mesma razão que utilizamos esses termos corriqueiros nos locais em que realizamos trabalho de campo, no sentido mesmo de que os sujeitos que as usam o fazem como modo quase de nomeação de uma prática e um estilo de vida que transborda a caixa, ou o conceito, ou a relação significante/significado.

Embora seja um tópico praticamente inédito dentro da Linguística Aplicada, o pós-humano incide diretamente na questão das disciplinas pertencentes às humanidades (BRAIDOTTI, 2013). Uma vez que, como Buzato (2018, p. 10) aponta, o sujeito pós-humano "vive num espaço de ambiguidade", a Linguística Aplicada se apresenta enquanto um campo rico para tratar o pós-humano por ser tanto trans quanto interdisciplinar.

Este ensaio está organizado a partir de um relato de um praticante de biobacking de performance em um pequeno evento de biobacking. Introduziremos a noção de cuidado de si, trabalhada por Foucault (1984 [2018]), pois acreditamos ser o modo de subjetivação recorrente no contexto apresentado no relato e que auxiliaria na compreensão da constituição de um sujeito pós-humano. Temos consciência de que há um grande trabalho analítico no sentido de tornar essa discussão palatável 
aos especialistas, e por essa razão desejamos apenas apontar, em forma ensaística neste texto, a possibilidade para ulterior reflexão em profundidade. Dito isso, apresentamos o conceito de pós-humanismo, trans-humanismo e ciborguismos para testar a argumentação de como o biobacking de performance se mostra uma prática fundamentada em alguns princípios de relativo apagamento da concepção humana clássica e na transformação desta em uma máquina produtiva, útil para o capitalismo atual. Em seguida, discorremos sobre o conceito de pós-humano crítico como uma resposta ao projeto trans-humanista, no sentido em que ele configura a possibilidade de aproveitarmos a potencialidade do ciborgue como construto teórico capaz de lidar com as diferentes subjetividades emergentes na contemporaneidade.

\section{AS EXPERIÊNCIAS DE BIOHACKER DE PERFORMANCE}

Com o estado atual dos estudos genéticos, temos um conhecimento mais detalhado da composição de nosso corpo e, consequentemente, de como ele funciona. Essa compreensão é utilizada por diferentes frentes com o objetivo de manipular a natureza humana e, talvez, modificá-la.

Um movimento chamado Quantified Self (SWAN, 2013) propõe que o indivíduo, utilizando mecanismos que quantifiquem sua vida, passe por um processo de autoconhecimento. Quantas xícaras de café ou quantas horas dormidas são unidades de medidas que podem trazer grandes informações sobre si mesmo. $\mathrm{O}$ uso dessas informações para manipular a potencialidade do corpo pode ser chamado de biobacking, embora haja uma certa discussão se poderia ser considerado como tal dentro dos grupos de biobacking.

A palestra de que falamos na introduções aconteceu em um pequeno evento de biobacking. O evento tinha a proposta de introduzir o tema aos interessados que não o conheciam. A primeira palestra foi sobre "Biobacking de Performance" doravante $\mathrm{BP}$, expressão que utilizaremos para nos referir à manipulação de hábitos de uma pessoa com o objetivo de alterar suas capacidades físicas e/ou cognitivas.

Intitulada "Minha experiência com biobacking de performance", a palestra ocorreu em uma pequena sala em São Paulo. A apresentação foi feita por um rapaz (aqui denominado Dragon), na faixa dos trinta anos e profissional da área da tecnologia da informação, que explicou ter sido convidado por um dos organizadores para apresentar como foi o uso de BP em sua vida. Praticante há pelo menos três anos, Dragon explicita ter uma vida regulada pelas dinâmicas de seu emprego: cursos no exterior e rotinas com horários pouco convencionais são frequentes em sua vida. 
Em sua palestra, Dragon introduz uma classificação dos tipos de biobacking, as "três grandes vertentes": o BP, o ciborgue e o "mais cientista". Enquanto os dois últimos envolvem implantes de mecanismos eletrônicos em corpos orgânicos ou manipulação genética, o primeiro, segundo Dragon, é o mais popular. Ele o define como sendo a prática de "mexer na tua alimentação, no teu sono, perder peso, várias coisas relacionadas a otimizar a máquina que é o corpo humano". O corpo como máquina.

Dragon explica a todos que a sua maior motivação para praticar o BP é a "dificuldade para me concentrar", o que o levou à decisão de que "precisava tomar uma atitude para diminuir isso". Falando sobre seu sofrimento com a falta de concentração desde criança, Dragon sente o peso dela no momento atual, com tantos objetos de consumo que chamam sua atenção e afetam sua concentração, assim como seu trabalho. Ele dá como exemplo a sua prática de programação que é prejudicada pela distração e o leva a recomeçar o processo muitas vezes.

O seu contato inicial com o BP foi a partir de leituras sobre o comportamento de pessoas dentro de Silicon Valley, onde funcionários chegariam a ficar vinte e quatro horas acordados com o propósito de cumprir suas tarefas. Contudo, Dragon só iniciou a prática quando precisou passar alguns meses em outro país, onde participaria de um curso de auto-aprimoramento e empreendedorismo. Lá, entrou em contato com algumas pessoas que já tinham adotado ou ainda mantinham a prática de regular a alimentação, e resolveu experimentar para ver como o seu corpo reagiria.

O tipo de BP utilizado por Dragon é o jejum intermitente, ou seja, a diminuição de refeições durante o dia, em um processo gradativo de espaçamento de tempo entre elas. Ele começou o jejum com um espaço de doze horas entre as refeições.

Durante a apresentação, explicitou todo o processo que seguiu durante os dias em que esteve no curso para disciplinar seu corpo: acordava às sete da manhã, bebia um suco, comia uma fruta ou uma bolacha, evitando ficar com o estômago vazio pelo dia inteiro, que seria composto por aulas, cursos e treinamentos. Manteve a ingestão de líquidos durante o dia, com água, água de côco, mas nada industrializado. Essa rotina, dentro do curso, ajudou-o a manter um ritmo mais produtivo.

Dragon especifica que é necessário um controle do indivíduo sobre o tempo e sobre a rotina de alimentação: é de extrema importância que se verifique como o seu próprio corpo responde. 
Concluindo sua fala, Dragon demonstra seu contentamento por ter conseguido atingir seu objetivo: ele percebeu um aumento em sua capacidade de concentração. Ele pode ver seu próprio corpo "entrar no automático" enquanto trabalhava ou estudava. Desde essa experiência, já chegou a ficar trinta e seis horas sem se alimentar, pois assim conseguiria lidar com o trabalho. Com o tempo, passou a sentir menos necessidade de se alimentar, consequência de sua "disciplina". Como próxima etapa no percurso de se aprimorar enquanto indivíduo, Dragon diz ter o projeto de passar a regular seu sono, treinar seu corpo para necessitar de menos horas de sono.

A fala de Dragon foi acompanhada por comentários entusiasmados com as possibilidades oferecidas pela prática do BP. Embora seja, em si, um exercício interessante, a partir do relato de Dragon, podemos perceber que há uma relação entre BP e um discurso de produtividade, desdobramento do sistema capitalista em que indivíduos como ele estão inseridos em uma espiral de controle, sublimação e consumo de corpos. E se o corpo é consumido no processo, ele precisa de algumas qualidades para habilitá-lo a isso.

Seu próprio interesse se fundamenta no desejo de se tornar mais focado e, consequentemente, mais produtivo, já que não teria sua performance prejudicada. A proposta do jejum era um meio para regular seu corpo e, assim, suportar longas jornadas de trabalho. Indivíduos como Dragon buscam ultrapassar as limitações de seus corpos para corresponder à necessidade das dinâmicas capitalistas atuais.

Para que possamos iniciar a reflexão mais a fundo sobre um processo de subjetivação que iria além do humano, é necessário que entendamos seus mecanismos. Dragon descreve o jejum como um conjunto de práticas que disciplinam seu corpo e, consequentemente, ele mesmo. Para abordar essas práticas, fundamentais para a constituição de um sujeito ciborgue apto para sustentar as relações capitalistas, baseamo-nos no conceito de cuidado de si de Foucault. Como o próprio filósofo explicita (2009), é importante compreender inicialmente as pequenas relações de poder, pois elas fundamentam as demais.

\section{QUEM EU ME TORNO POR MEIO DE MEU CORPO: O CUIDADO DE SI}

Ao explicar sua pesquisa, Foucault (2009) menciona que ela foi guiada por seu interesse pelos modos de subjetivação, de transformação de seres humanos em sujeitos. Ele passou pelos modos da investigação, que busca o estatuto de ciência, e da objetivação do sujeito, de sua constituição em diversos campos de saber. Por 
último, o filósofo se preocupou com o modo como "um ser humano torna-se um sujeito" (FOUCAULT, 2009, p. 231).

Esses modos são compostos por certas tecnologias estudadas por Foucault. Não há uma estrutura hierárquica entre elas, pois nunca atuam sozinhas, tendo suas ações, sobre o sujeito, entrelaçadas e mutuamente implicadas (LOURENÇÃO, 2010). As tecnologias têm sempre uma relação com o ato de dominação, seja de uma instituição sobre o sujeito ou deste sobre si mesmo e sobre outros. De acordo com o autor, cada uma atuaria no sentido de modificar o indivíduo, não apenas no sentido óbvio de aqusição de certas habilidades, mas também de aquisição de certas atitudes (FOUCAULT, 1988).

Entre as tecnologias, está a tecnologia de si, referente ao último modo de subjetivação estudado por Foucault. Ela é adotada pelo próprio indivíduo para agir sobre si, sujeitando-se a um ou mais discursos. Assim como o biohacking de performance poderia exigir do indivíduo que o pratica, algumas ferramentas são utilizadas para observar, controlar e gerenciar suas performances. Foucault aponta que, por meio de operações como o registro de suas atividades em um diário ou exercícios físicos, o sujeito transforma a si mesmo com o objetivo de alcançar "um certo estado de felicidade, de pureza, de sabedoria, de perfeição ou de imortalidade" (FOUCAULT, 1988, p. 18).

O objetivo das práticas de Dragon se aproximam do que é dito por Foucault sobre as tecnologias de si. O caso de Dragon é pontual e individual: é em seu próprio corpo que ele age para se configurar enquanto sujeito legítimo do capitalismo avançado; se ele tem a consciência de como o capitalismo usa seu corpo ou não, isso pode ser deixado de lado neste momento. No entanto, ele avalia a disposição de seu corpo, que é controlada por meio da inserção ou da retirada de alimentos em sua rotina. No final, ele busca estar o mais próximo possível da perfeição, dentro de seu ponto de vista, claro.

Uma das expressões das tecnologias de si descritas nos textos da antiguidade greco-romana por Foucault (1984 [2018]), é o da epimeleia beautou ou o cuidado de si. Este se fundamentou tanto na preocupação quanto na ocupação consigo mesmo. $\mathrm{O}$ cuidado seria o complemento da famosa afirmação do templo de Delfos "conhece a ti mesmo". No início, o cuidado de si era uma atividade defendida por filósofos, como Epiteto, que o via como elemento constituinte do humano, pois este usaria a razão para se tornar objeto de suas próprias análises e, logo, poderia corrigir qualquer conduta moral indesejada de um sujeito. Como exemplo, Platão via o cuidado de si como uma preparação necessária para uma vida política. O processo de conhecer a 
si, analisar seus pensamentos e suas ações é um meio de cuidar de si, agir sobre seu espírito e seu corpo para regularizá-lo dentro do que era então esperado.

Um dos primeiros exemplos de práticas de medição e análise de si trazido por Foucault é a análise dos sonhos. Estes eram vistos como um canal de premonições que, caso o indivíduo prestasse atenção e os interpretasse corretamente, poderia saber como agir quanto ao que viria a acontecer em sua vida. Na antiguidade, os homens precisavam adotar essa prática, "já que as noites dizem aquilo de que os dias serão feitos, é bom, a fim de conduzir a própria existência de homem, de dono da casa, de pai de família, saber decifrar os sonhos que então se produzem" (FOUCAULT, 1984 [2018], p. 35). As pessoas utilizavam livros, como o de Artemidoro, para guiar suas interpretações.

Os sonhos também serviam para que o sujeito entendesse a si mesmo. Eles foram vistos como um modo de traduzir o que "na ordem do corpo, é falta ou excesso, e o que, na ordem da alma, é medo ou desejo" (FOUCAULT, 1984 [2018], p. 15), ou seja, ele poderia entender o que o angustiava ou quais necessidades físicas ele precisava saciar para que ficasse bem. Contudo, por mais que fosse implícita a relação entre o corpo e o subjetivo, é por meio do conceito de pathos que o cuidado com o corpo, específico da medicina, passa a ser vinculado ao cuidado da alma. $\mathrm{O}$ pathos

(...) tanto se aplica à paixão como à doença física, à perturbação do corpo como ao movimento involuntário da alma; e num caso como no outro, refere-se a um estado de passividade que, para o corpo, toma a forma de uma afecção que perturba o equilíbrio de seus humores ou de suas qualidades e que, para a alma, toma a forma de um movimento capaz de arrebatá-la apesar dela própria. A partir desse conceito comum foi possível construir uma grade de análise válida para os males do corpo e os da alma. (FOUCAULT, 1984 [2018], p. 70)

O corpo passou a ocupar uma posição importante em relação à alma. Doenças poderiam afetar não só a saúde do corpo, como também poderiam perturbar o "equilíbrio de seus humores ou de suas qualidades" (FOUCAULT, 1984 [2018], p. 70). Assim, desenvolveu-se um modelo de cuidado que permitiria uma abordagem dupla, tanto do corpo quanto da alma.

O conceito de pathos também marca o momento em que o discurso da medicina se entrelaça com o discurso ético. De acordo com Foucault (1984 [2018]), a medicina não regulava apenas a saúde dos sujeitos, mas regras de como o indivíduo deveria viver para ser reconhecido enquanto sujeito. A alimentação deveria ser leve antes das relações sexuais para as mulheres, por exemplo. Desse modo, o cuidado de si se tornou uma prática de vigília e de agir sobre si mesmo por meio de seu corpo. 
Embora muitas das atividades relativas ao cuidado de si dos antigos se assemelhem aos cuidados relatados por Dragon, não é o mesmo tipo de sujeito que as práticas têm como objetivo. Enquanto os antigos buscavam constituir a si mesmos como sujeitos de uma sexualidade ou éticos, os biohackers seguem uma outra agenda, que visa um sujeito produtivo, menos humano e, talvez, mais máquina. Podemos supor isso, uma vez que o jejum intermitente tenta eliminar uma necessidade básica humana: a fome.

O ponto de convergência das ideias de superar os limites biológicos do humano e os processos de produção capitalista seria, para nós, o movimento trans-humanista. Este, com a sua agenda para alcançar o pós-humano, a nova etapa evolucionária do ser humano, adota a figura do ciborgue como meio para tal.

\section{AS DIFERENTES FACETAS DO PÓS-HUMANISMO}

Em sua fala, Dragon especifica as três grandes vertentes atuais do biobacking. Mesmo com suas diferenças técnicas, elas operam sobre um elemento comum: o humano. Manipulando DNA ou apenas controlando o funcionamento do corpo por meio de dietas, os biohackers esticam seus limites, questionando a sua natureza e, assim, procurando trespassar as bordas que delimitam o humano.

O além do humano é chamado de pós-humano. Este, porém, tornou-se um termo guarda-chuva (PENNYCOOK, 2016) para diferentes concepções: desde filosóficas das teorias feministas (BRAIDOTTI, 2013) até as que se desdobram dos estudos da inteligência artificial (TEGMARK, 2017). Nesta seção, apresentamos uma conceitualização do que seriam o pós-humanismo - como um momento em que o humano está em crise -, o trans-humanismo e o ciborguismo. No final, trataremos do pós-humano crítico.

\subsection{Pós-humanismo}

Segundo Braidotti (2013), tanto o desenvolvimento tecnológico quanto o econômico foram pontos de pressão sobre o humano, sob os quais ele se transformou. Com o pós-humanismo, inicia-se um período em que os indivíduos podem propor diferentes representações para nós, humanos em demasia.

A noção de ser humano era, até então, naturalizada e dificilmente questionada. Embora possamos muitas vezes considerar que o humano equivale às suas características físicas enquanto espécie, a sua representação foi constituída durante um período conhecido como Humanismo. De acordo com Braidotti (2013), 
o humano como centro do mundo era homem, branco e, provavelmente, ao menos durante algum tempo, hétero. Em conjunto com essa narrativa, havia o eurocentrismo característico da época que inevitavelmente constituiu a representação o homem branco e cidadão europeu como o ideal humanista.

$\mathrm{O}$ ato de constituir uma representação ideal se desdobra na construção de um Outro que, nesse caso, torna-se uma entidade negativa, mas fundamental para a relação dialética que constitui o humano, desenhando a linha que separa o que ele é do que ele não é. Essa dicotomia é um dos grandes problemas da tradição humanista, já que, de acordo com Braidotti (2013, p. 15), "enquanto diferença significar inferioridade, ela adquire conotações tanto essencialistas quanto letais para pessoas que são marcadas como outras.".

O Outro incluía mulheres, negros, homossexuais, animais, mas, atualmente, podemos acrescentar tanto máquinas quanto o próprio planeta a essa lista. O discurso antropocêntrico destitui de legitimidade esses sujeitos e fundamenta práticas de exclusão por toda a história.

Como resposta ao Humanismo e às suas narrativas de exclusão, houve um movimento que procurou desconstruir e repensar a noção de humano, entre outras concepções herdadas historicamente. Conhecido como anti-humanismo, ele foi constituído pelo trabalho de autores como Michel Foucault, Gilles Deleuze e Jacques Derrida (BRAIDOTTI, 2013).

O movimento anti-humanista, cujo ápice talvez tenha se dado com os desdobramentos dos movimentos políticos de 1968, não argumentava contra a espécie humana, mas sim contra a sua excepcionalidade perante outros elementos, e coisas, e poderes, e saberes, com os quais o humano - ocidental, bem entendido - convive. Considerando que a noção de normalidade vinda do ideal de humano é baseada em um construto sócio-cultural e não em uma verdade absoluta, o anti-humanismo advoga pelos sujeitos não-unitários, fragmentados. Sua maior contribuição foi resistir e minar a força da dialética do Outro, cuja diferença era marcada como negativa.

Apesar de o anti-humanismo promover um debate crítico e necessário, ele não trouxe, necessariamente, contribuições para a situação que se discutia à época. De acordo com Braidotti (2013), o anti-humanismo acaba se debruçando muito sobre a questão da crise do humano e sobre o processo de desconstrução do discurso humanista, permitindo novas subjetividades fossem legitimadas e, destacando alguns pontos de extremo valor como a liberdade do indivíduo. O pós-humanismo

4. (Original) "in so far as difference spells inferiority, it acquires both essentialist and lethal connotations for people who get branded as others". 
torna-se o marco da superação dessa disputa entre Humanismo e Anti-humanismo, e tenta "traçar uma estrutura discursiva diferente, buscando olhar de modo mais positivo as novas alternativas" (BRAIDOTTI, 2013, p. 37); por exemplo, pensar a constituição de uma subjetividade em rede.

Entre as novas alternativas atuais, encontramos o trans-humanismo. O design de um humano mais potente vai ao encontro do projeto desse movimento e de seu resultado final: o pós-humano. Sim, é o trans-humanismo que constitui a prática do BP, mas pouco se preocupa em ter um olhar crítico sobre as condições sociais decorrentes da formação de um pós-humano. Neste caso, o pós-humano nada tem a ver com mais liberdade, com uma valorização do humano. Tem a ver com uma variação de potência para, e não de potência em si. Voltaremos a isso na conclusão.

\subsection{0 trans-humanismo}

A dieta adotada por Dragon envolve um sistema regido por valores, tempo e quantidades. Ela funciona como uma tecnologia que ele adotou com o objetivo de aprimorar a si mesmo. Transformar a natureza humana por meio de tecnologias de modo a se tornar "melhor" é o objetivo principal do trans-humanismo, e pode ser considerado um movimento internacional que parte da premissa de que "as tecnociências contemporâneas podem aperfeiçoar as capacidades humanas e melhorar ou eliminar tais verdades humanas [demasiado humanas] como a mortalidade ${ }^{5 \prime}$ (HAYLES, 2011, p. 217).

O trans-humanismo advoga pela intervenção do ser humano em seu processo evolutivo. A partir de tecnologias e sociotécnicas como a nanotecnologia, a biotecnologia, as tecnologias de informação e de comunicação que possibilitam um cenário em que o humano é projetado (TIROSH-SAMUELSON, 2011), constróise uma ideologia que considera o humano capaz de se tornar um pós-humano, ou seja, aquele que transcende sua natureza a partir de sua própria intervenção. Como Tirosh-Samuelson descreve, "na era do pós-humano, os humanos não serão mais controlados pela natureza; ao invés disso, eles é que controlarão a natureza ${ }^{6 \prime \prime}$ ( $\mathrm{p}$. 20, 2011).

Junto com Julian Huxley, outros dois cientistas, John Burdon Sanderson e John Desmond, desenvolveram nos anos 20 na Inglaterra ideias baseadas no progresso científico como principal fator evolutivo da espécie humana. Huxley

5. (Original) "(...) proposition that contemporary technosciences can enhance human capabilities and ameliorate or eliminate such traditional verities as mortality".

6. (Original) "(...) in the posthuman age, humans will no longer be controlled by nature; instead they will be the controllers of nature". 
tinha como objetivo final atingir o pós-humano, tratando o período entre o humano e o pós como o trans-humano.

Adotamos o termo trans-humano para definir todo o movimento de grupos e de seitas que defendem esses pontos, pois acreditamos que abrange melhor as ideias e a própria situação atual dos projetos. Ao contrário do que defendem, é difícil acreditar ser possível transcender a condição humana completamente, ao menos no sentido de constituir um humano novo, totalmente imune aos caprichos da natureza e às vicissitudes da vida biológica não gerida.

O discurso mais atual do trans-humano tem seu início nos anos 90, quando alguns "tecno-entusiastas apresentaram uma visão apocalíptica na qual uma ruptura, conhecida como 'a Singularidade', trará fim à existência humana, dando abertura a uma espécie de inteligências artificiais que estarão competindo com a humanidade ${ }^{7 \prime}$ (TIROSH-SAMUELSON, p. 23). Com o desenvolvimento das pesquisas transhumanistas, percebeu-se que, de acordo com Hayles (1999), o pós-humano proposto por elas poderia ser caracterizado a partir de quatro pontos. Ele (1) acaba privilegiando padrões de informação sobre a matéria; (2) posiciona a consciência como algo central no ato de se existir; (3) toma o corpo como uma prótese que pode ser manipulada e qualquer modificação é parte do processo evolutivo; e (4) pressupõe uma articulação ou um acoplamento com máquinas inteligentes. Contudo, a autora acredita que a construção de um pós-humano precisa ser indagada por um olhar crítico; e seria ideal que houvesse uma maneira de aproveitar as oportunidades que o avanço tecnológico nos proporciona sem que leve à perda do material, neste caso, do corpo.

Embora o trans-humanismo seja uma das vertentes mais conhecidas, na atualidade, quando se trata de pós-humano, alguns autores se opõem a ele. Hayles (1999) e Braidotti (2013), preocupadas com o caminho escolhido pelos transhumanistas, propõem um pensamento mais crítico quanto ao desenvolvimento tecnológico e quanto a seus objetivos. Hayles defende, por exemplo, não ser possível pensar uma subjetividade desassociada de um corpo, o que vai de encontro a um dos principais projetos dos trans-humanistas: a datificação da mente e a vida eterna de uma consciência inserida em um computador.

A crítica de Hayles vai ao encontro do argumento do filósofo Slavoj Žižek que mostra como o trans-humanismo ignora uma questão crítica ao poder das

7. (Original) "technoenthusiasts have offered an apocalyptic view in which a rupture, referred to as 'the Singularity', will bring an end to human existence, ushering instead an autonomous, artificial intelligent species that will be in competition with humanity". 
instituições, tanto estatais quanto privadas, sobre o processo que conduz ao póshumano. $\mathrm{O}$ trans-humanismo pressuporia um sujeito isolado da ideologia, pois

[e]les levam ao extremo a cisão entre o "sujeito do enunciado" e o "sujeito da enunciação": de um lado, como objeto de minhas intervenções, sou um mecanismo biológico cujas propriedades, inclusive as mentais, podem ser manipuladas; de outro, estou (ajo como se estivesse) isento, de certo modo, dessa manipulação, como indivíduo autônomo que pode fazer a escolha certa. Mas e se o círculo se fechar e meu poder de decisão autônoma já tiver sido "mexido" pela manipulação biogenética? (ŽIŽEK, 2012, p. 238)

Ou seja, o trans-humanismo caminha com seus projetos considerando uma autonomia suprema do indivíduo sobre si mesmo. Esta seria exercida por meio da constituição de si mesmos em ciborgues, seres cujas capacidades inerentes ao ser humano foram melhoradas ou os problemas apagados. Tanto a força quanto o intelecto, até à morte, todos seriam modificados, de um modo ou de outro, no ciborgue.

O relato de Dragon ilustra bem como a relação com uma tecnologia pode servir para formar um ciborgue que tem, sim, suas capacidades aumentadas, mas para cumprir um objetivo: atender às demandas do mercado. A figura do ciborgue carrega a virtualidade de ser tanto uma máquina produtiva quanto uma metáfora em que as diferenças encontram seu lugar. Embora a história do termo "ciborgue" reforce mais a máquina, propomos não ignorar a metáfora.

\subsection{0 ciborguismo}

Ciborgue. A palavra tem um quê futurista que leva muitas pessoas a descartála como um produto de imaginações ficcionais. Embora estejamos, aqui, tratando o ciborgue como um construto teórico que nos permite apreender a relação humanotecnologia estabelecida por Dragon com o seu regime, por outro lado, os ciborgues reais têm estado entre nós por um longo tempo. De acordo com Kunzru (2000, p. 121-126), um dos primeiros ciborgues de que temos notícia foi um rato de laboratório de um programa experimental do Hospital de Rockland em Nova York, no final dos anos cinquenta. Implantou-se no corpo do rato uma pequena bomba osmótica que injetava doses controladas de substâncias químicas que alteravam sua fisiologia.

O rato de Rockland é um dos astros de um artigo intitulado "Ciborgues e espaço", escrito por Manfred Clynes e Nathan Kline, em 1960. Essa dupla, formada por um engenheiro e um psiquiatra, inventou o termo "ciborgue" (abreviatura de "cybernetic organism") para descrever o conceito de um corpo humano ampliado, isto é, alguém mais bem adaptado aos rigores de uma provável viagem espacial. Clynes 
e Kline imaginavam um futuro astronauta cujo coração seria controlado por injeções de anfetaminas e cujos pulmões seriam substituídos por uma "célula energética inversa", alimentada por energia nuclear.

Em meados dos anos sessenta, os ciborgues representavam um grande negócio, com milhões de dólares da Força Aérea estadunidense sendo canalizados para projetos de construção de exoesqueletos, braços robóticos do tipo mestreescravo, dispositivos de bio-feedback e sistemas especializados. Por outro lado, apesar de todo o dinheiro gasto nessas geringonças, a impressão dominante deixada por velhos artigos técnicos sobre o ciborgue era a de que se tratava de um tipo bastante caro de ficção científica, absolutamente distante de ser realizada (KUNZRU, 2000, p. 122-123).

Não foram somente os militares a se deixarem seduzir pelas possibilidades do ciborgue. O sonho de melhorar as capacidades humanas por meio de uma reprodução seletiva e eugênica (MONTEIRO, 2012, p.106) tem constituído, desde muito, um item obrigatório no lado sombrio da literatura médica ocidental. De acordo com Janine Ribeiro (2003, p.15-36), esse sonho militar vem se tornando possível por uma reorientação de diversos componentes, como o entendimento das reentrâncias entre a cultura e a natureza (LATOUR, 1994;VIVEIROS DE CASTRO, 1996), o desenvolvimento das ciências em uma busca de consonância com a construção de máquinas militares, e centralmente numa reorientação do sujeito, o qual tornou-se coisa para se livrar do peso da decisão em relação ao próprio destino. Vinda de um contexto relativamente social ao longo da primeira metade do Séc. XX, é especificamente a medicina que passa a adquirir, no pós-Segunda Guerra, os contornos biologicistas que nos afetam nos dias de hoje. A exemplo, o uso de antidepressivos e de uma perspectiva atomista do cérebro humano colocam em questão a resolução de conflitos via drogas e, consequentemente, uma reconfiguração da vida social calcada centralmente no indivíduo, drogado e anestesiado - ou, então, resolvido a partir de implantes cerebrais ${ }^{8}$.

$\mathrm{O}$ ciborgue se transformou de uma fantasia acadêmico-militar em assunto do horário nobre da TV estadunidense. Obviamente, robôs, autômatos e pessoas artificiais tinham feito parte da imaginação ocidental desde pelo menos o Iluminismo. O lendário construtor de autômatos Wolfgang von Kempelen construiu um turco de lata que jogava xadrez e que se tornou a coqueluche da Europa napoleônica (KIM, 2013). O Dr. Frankenstein de Mary Shelley construiu - a partir de partes do corpo - um ser vivo que foi ativado por eletricidade, vivendo uma vida desgraçada desde

8. http://www.pewinternet.org/2016/07/26/public-opinion-on-the-future-use-of-brain-implants/ (Acesso em setembro de 2016) 
que aprendeu a se comunicar com os homens. A monstruosidade de Frankenstein não vem de sua configuração idiossincrática, mas sim do fato de simbolicamente inverter a criação, e não porque o Dr. Frankenstein aspire a controlar o poder divino da vida, mas porque o híbrido produz vida a partir do que já consumou a existência e está destinado a transformar-se novamente em terra, em pó, em nada. É nessa inversão que pode ser encontrada uma de suas monstruosidades. Não a monstruosidade daquele que se imagina como monstro - a do qual a narrativa trata mais diretamente -, mas a do humano dentro de um circuito de pequenas monstruosidades que se desdobram à revelia do desejo.

Recentemente, a possibilidade de fabricar humanos melhorados, ampliando suas capacidades por meio de dispositivos artificiais, tornou-se relativamente certa. E uma coisa em específico torna o ciborgue de hoje fundamentalmente diferente de seus ancestrais mecânicos: a informação. Os ciborgues, explica Haraway (2009), são máquinas de informação. Eles trazem dentro de si sistemas causais circulares, mecanismos autônomos de controle, processamento de informação - são autômatos com uma autonomia embutida.

Sobre uma proposta de classificação, certa taxonomia foi estabelecida (GRAY, MENTOR e FIGUEROA, 1995, p.3), e ela diz que podemos classificar quatro modos de reconhecimento de uma configuração ciborgue: a restauradora: restaura funções, órgãos e membros perdidos; a normalizadora: devolve os seres a uma indiferente normalidade; as reconfiguradoras: produzem criaturas pós-humanas, que são iguais aos seres humanos e igualmente diferentes deles; e as melhoradoras: criaturas melhoradas.

Os ciborgues nos ajudam a pensar nas múltiplas intervenções e interseções entre o humano e a máquina; e especialmente, de um lado na mecanização e na eletrificação do humano; de outro, na humanização e subjetivação da máquina, circuito em expansão e complexificação desde muito tempo. Simultaneamente, o conceito se estica e comporta sujeitos cujos processos de subjetivação envolvem relação informacionais, como as mencionadas por Haraway.

Assim, o ciborguismo é a configuração que a agenda trans-humanista adota para pensar as etapas necessárias até seu objetivo final. Em sua história, a figura do ciborgue, ou seja, do humano cujas funções foram aprimoradas com tecnologia, é constituída pelo desejo da utilidade. Seja para tolerar viagens intergaláticas e, assim, propagar o domínio do ser humano sobre o universo, seja como uma arma mais potente para os exércitos, as modificações nunca tiveram o objetivo de tornar as vidas das pessoas mais agradáveis. 
A partir do relato de Dragon, podemos traçar pontos que convergem para o seu objetivo de se tornar uma máquina produtiva. Sem fome e, talvez, futuramente, sem sono, ele poderá acompanhar o ritmo de produção de um mercado global e que não tem limites físicos-biológicos. Contudo, dentro do espectro do póshumano, não existem apenas as possibilidades que procuram apagar a humanidade do indivíduo.

O ciborgue é o ponto de encontro de diferenças que nele, também, não estão mais delimitadas ou desenhadas: os diferentes se perdem e se transformam em um único elemento: espaço para as subjetividades que desafiam as dicotomias clássicas. $\mathrm{O}$ ele ou o ela. $\mathrm{O}$ humano e o animal ou o humano e a máquina. Esse ciborgue pode ser alcançado caso não siga a agenda instrumentalista neo-liberal do transhumanismo. Se o ciborgue pode abrir caminho para um novo humano, é necessário que partamos da conceituação de um pós-humano crítico.

\subsection{0 pós-humano crítico}

A perfeição implícita no uso do jejum intermitente por Dragon tem como objetivo manter sua produção. No entanto, durante sua fala, ele não questiona o peso do que está disposto a dar em troca e não reflete criticamente sobre os motivos que o levam a tal decisão. Por trás de seu desejo, não há uma questão de bem-estar pessoal ou comunitário ou uma transformação moral sua. Deixar de sentir fome ou sentir menos sono é um apagamento das necessidades biológicas do corpo. O trans-humanismo, que tem como um dos projetos principais a imortalidade por meio da digitalização da consciência, desloca o corpo para uma posição patológica: a de um problema a ser tratado e eliminado.

Em contrapartida, uma vez que a condição pós-humana nos leva a repensar, segundo Pennycook (2016, p. 5), "o relacionamento com todos os Outros que sofreram com a construção da humanidade (deuses, máquinas, objetos, coisas, animais, monstros, mulheres, escravos, etc.) (...) enquanto também modifica a ideia do que o 'ser humano' significa"', a perspectiva crítica do pós-humano argumenta por uma compreensão diferente do sujeito. $\mathrm{O}$ pós-humano crítico não está preocupado em apagar o que há de "humano". Ele busca abarcar mais subjetividades que se formam no entrelaçamento do humano com agentes não-humanos.

Assemelhando-se à crítica de Latour (2000) ao ato de ignorar a presença dos não-humanos e seu papel na constituição do que chamamos de "sociedade",

9. (Original) A posthumanist position seeks a rethinking of the relationship to all those Others that suffered in the construction of humanity (gods, machines, objects, things, animals, monsters, women, slaves, and soon (...) while also shifting the idea of what it means to be human. 
a ideia de um pós-humano crítico abraça os não-humanos exatamente como seu diferencial. Ao contrário do sujeito clássico, cuja subjetividade se dá por meio de sua relação com seus iguais, o indivíduo passa a ser sujeito (e a subjetivar a si mesmo) em relação com máquinas, animais e até mesmo com o planeta.

Uma vez que o sujeito pós-humano contrasta diretamente com o sujeito clássico, ele não tem uma forma idealizada, mas, sim, diferentes expressões do que seria o pós-humano. Baseando-se na ideia de devir, apresentada por Gilles Deleuze, Braidotti (2013) apresenta três dessas expressões: o devir-animal, o devir-máquina e o devir-planeta. Nenhum desses está fechado, mas sempre em processo de transformação. Se pensarmos no caso do relato de Dragon, podemos considerar o sujeito ciborgue como uma dessas expressões do pós-humano, já que se relaciona com diferentes tecnologias para constituir-se enquanto sujeito. Um sujeito decorrente de um período tão tecnologizado como o que vivemos agora.

Desse modo, ao contrário do trans-humanismo que advoga em favor de um super-humano potencializado por tecnologias, o pós-humano crítico não propõe uma versão final e atualizada do humano. Ao invés de tentar propor uma resposta definitiva e certa, o pós-humano crítico é

uma ferramenta geradora que nos auxilia a repensar a unidade básica de referência para o ser humano na era da biogenética conhecida como 'antropoceno', o momento histórico em que o humano se tornou uma força geológica capaz de afetar toda a vida deste planeta ${ }^{10}$ (BRAIDOTTI, 2013, p. 5)

Em meio a esse cenário, os indivíduos se apropriam de práticas, experimentam meios de se legitimarem como sujeitos. Não há um tipo específico de tecnologias para isso, o que permite diferentes experiências. Enquanto Dragon utiliza o jejum, temos o exemplo de indivíduos que, a partir das redes sociais, inserem-se no discurso como sujeitos políticos legítimos (KAWANISHI, 2016).

Independentemente da expressão que o pós-humano crítico encontrar, seu objetivo está mais alinhado a romper com a delimitação do que é e do que não é legítimo, enquanto categorias definitivas, do que reforçar a posição central do humano perante os não-humanos. Ele personifica o desejo de lidar com o sujeito em seu exercício de ser que toma, na atualidade, diferentes formas. E enquanto personificação de desejo, possui diferentes e imprevistas possibilidades.

10. (Original) (...) posthuman theory is a generative tool to help us re-think the basic unit of reference for the human in the bio-genetic age known as 'anthropocene', the historical moment when the Human has become a geological force capable of affecting all life on this planet. 


\section{CONSIDERAÇÕES FINAIS}

No final de sua fala, Dragon apresenta o último slide com as suas considerações sobre a sua experiência. A tela mostra, então, duas conclusões: houve uma melhora na sua capacidade de focar em uma atividade e houve perda de peso. A ausência de qualquer ato reflexivo sobre sua prática e os caminhos adotados por ele, assim como nos possíveis resultados, fica patente no final da apresentação. Isso acontece porque os indivíduos, constituídos pelo discurso neo-liberal, não acreditam ser necessário se preocupar com tais questões. Como Žižek apontou, eles se veem distantes da manipulação que eles mesmo aplicam em si. Como resultado, não há tanta clareza quanto ao alcance e aos limites de tais práticas [corporais e de vida]. No entanto, os corpos do capitalismo tardio estão em movimento, fazendo conexões inesperadas com os não-humanos.

Temos a consciência de que este trabalho tenta unir pontas soltas, pois não há a possibilidade de aprofundar a discussão sobre o biobacking de performance como cuidado de si, e muito menos de abordar os pormenores que permeiam tal discussão neste momento - razão pela qual nos valemos do modo ensaístico de argumentação. Contudo, como uma proposta de discussão, pensamos que cumprimos esse propósito, já que iniciativas como a de Dragon estão se popularizando e, com a intensa presença de tecnologias em nossas vidas, ficou mais fácil o surgimento de outras práticas com intuitos semelhantes e precisamos de modos de reflexão que toquem esses objetos em profusão.

Ao ser adotado por indivíduos como Dragon, o BP acaba constituindo-os como sujeitos de um discurso pouco humanizado. O ciborgue construído pelo discurso capitalista mantém as diferenças expostas e tenta apagar apenas o lado humano com o objetivo de maquinizá-lo. Além disso, o relato de Dragon serviu como o fio condutor para que tentássemos tratar da questão do pós-humano, chamando a atenção para o fato de que esse novo campo passou a ser assumido tanto por grandes corporações e laboratórios, quanto pelas ciências duras e biológicas. Enquanto isso, as Humanidades, conjunto de saberes diretamente afetados pela transformação e questionamento do humano, ainda se encontra pouco engajada nessas discussões, ao menos segundo os dados de que dispomos até este momento.

O movimento trans-humanista ganha força e, com ele, a noção de que o nosso futuro está depositado nas mãos das tecnologias, junto a todo um incentivo à constituição de um sujeito mais produtivo, de um corpo mais útil e, consequentemente, menos político. Noções como a de pós-humano crítico nos dão base para acompanhar as reflexões sobre as próximas etapas do humano, porém de um modo que seja mais acolhedor e menos idealizado. Preocupado com 
os diferentes sujeitos, o pós-humano crítico legitima os sujeitos excluídos pelas antigas dicotomias e pelas dinâmicas do capital. E, dentro de uma analítica do capitalismo, importa saber o que e como estão se dando os processos de adaptação dos humanos aos novos modos de produção cujo foco é justamente a produção de novos humanos.

\section{REFERÊNCIAS}

BRAIDOTTI, R. (2013) The Postbuman. Cambridge: Polity Press.

BUZATO, M. (2018) Ética e linguagem nos encontros pós-humanos. In: Anais I Congresso Internacional em Humanidades Digitais, Rio de Janeiro.

FOUCAULT, M. (2018) A bistória da sexualidade 3: o cuidado de si. Rio de Janeiro/São Paulo: Paz e Terra.

FOUCAULT, M. (1988) Technologies of the self. In: Technologies of the self: a seminar with Michel Foucault. The University of Massachusetts Press.

FOUCAULT, M. (2009) O sujeito e o poder. In: Hubert L. Dreyfus e Paul Rabinow. Michel Foucault - uma trajetória filosófica. Rio de Janeiro: Forense Universitária.

GRAY, CHRIS; HABLES, FIGUEROA-SARRIERA, HEIDI, L; MENTOR, STEVE. (1995). The Cyborg Handbook. London, Routledge.

HARAWAY, D. (2009) Manifesto Ciborgue. In: Hari Kunzru, Donna Haraway, Tomaz Tadeu da Silva (organização e tradução). Antropologia do Ciborgue: as vergiens do pós-humano. Belo Horizonte: Autêntica.

HAYLES, N. K. (1999) How We Became Posthuman: virtual bodies in cybernetics, literatures, and informatics. Chicado: The University of Chicago.

HAYLES, N. K. (2011) Wrestling with Transhumanism. In: H+/-: Transhumanism and Its Critics. Metanexus Institute.

KAWANISHI, P. (2016) Identidade e autoria no ciberespaço: os dizeres de um autor sem nome. Dissertação de mestrado. Unicamp. 
KIM, Joon Ho. (2013). O estigma da deficiência física e o paradigma da reconstrução cibernética do corpo. Tese de doutorado em Antropologia Social. Faculdade de filosofia, letras e ciências humanas, FFLCH USP, São Paulo

KUNZRU, Hari. (2000). Genealogia do Ciborgue. Hari Kunzru, Donna Haraway, Tomaz Tadeu da Silva (organização e tradução). Antropologia do Ciborgue: as vergiens do póshumano. Belo Horizonte: Autêntica.

LATOUR, Bruno. (2000) Ciência em ação: como seguir cientistas e engenheiros sociedade afora. Tradução de Ivone C. Benedetti. São Paulo: Editora UNESP.

LATOUR, Bruno. (1994). Jamais fomos modernos: ensaio de antropologia simétrica. Tradução de Calors Irineu da Casta. Rio de Janeiro: Editora 34.

LOURENÇÃO, Gil Vicente Nagai. (2019). Marko Synésio Alves Monteiro. Os dilemas do humano: reinventando o corpo numa era (bio)tecnológica. São Paulo: Anablume, 2012. Horizontes Antropológicos, v. 25, n. 53, p. 421-426.

LOURENÇÃO, Gil Vicente Nagai. (2016). O Espírito Japonês: esboço para uma arqueologia etnográfica do Ki. Tese de Doutoramento em Antropologia Social, Universidade Federal de São Carlos..

LOURENÇÃO, Gil Vicente Nagai. (2010). Identidades, práticas e moralidades transnacionais: etnografia da esgrima japonesa no Brasil /São Carlos : UFSCar.

MONTEIRO, Marko Synésio Alves. (2012). Os dilemas do bumano: reinventando o corpo numa era [bio]tecnológica. São Paulo, Annablume.

PENNYCOOK, A. (2016). Posthumanist Applied Linguistics. Applied Linguistics, p. 1-18. Oxford University Press.

SWAN, M. (2013) The quantified self: fundamental disruption in big data science and biological discovery. In: Big Data, vol. 1, n. 2.

TEGMARK, M. (2017). Life 3.0 - being human in the age of artificial intelligence. New York: Alfred A. Knopf.

TIROSH-SAMUELSON, H. (2011) Engaging Transhumanism. In: H+/-: Transhumanism and Its Critics. Metanexus Institute.

VIVEIROS DE CASTRO, Eduardo. (1996). Os pronomes cosmológicos e o perspectivismo ameríndio. Mana 2(2):115-144. 
ŽIŽEK, S. (2012). Vivendo no fim dos tempos. São Paulo: Boitempo.

Recebido: 1/06/2019

Aceito: 19/07/2019

Publicado: 1/08/2019 